\title{
1-year prospective real life monitoring of asthma control and quality of life in Italy
}

\author{
Claudio Terzano ${ }^{1}$, Giovanni Cremonesi ${ }^{2}$, Giuseppe Girbino ${ }^{3}$, Eleonora Ingrassia ${ }^{2}$, Serafino Marsico4,

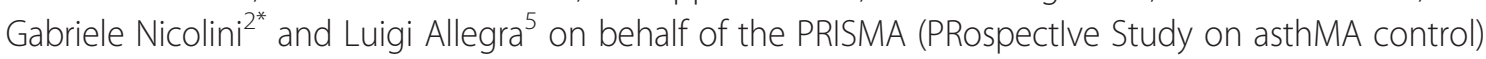 \\ Study Group
}

\begin{abstract}
Objectives: The study aimed at prospectively evaluating the evolution of asthma control in Italy, to evaluate the reasons for lack of asthma control, perceived quality of life (QoL) and association with level of asthma control, the impact of pharmacological treatment, the number of exacerbations and the healthcare resource consumption.

Methods: PRISMA (PRospectlve Study on asthMA control) was an observational study performed in asthmatic patients including a cross-sectional phase and a 12-month prospective phase. Asthma control was assessed with the Asthma Control Test ${ }^{\mathrm{TM}}$ (ACT) and QoL was evaluated with EuroQoL-5D questionnaire filled in and collected during 5 clinic visits together with all the other data.

Results: The prospective phase included 1017 patients with uncontrolled (55.7\%) or partly controlled asthma (44.3\%). Out of the 739 patients evaluable after 12 months, 22.2\% achieved full asthma control (ACT score $=25)$ and 58.7\% reached a good control (ACT score: 20-24). The improvement in asthma control was associated with improved QoL and reduced hospital visits. The main reasons for lack of asthma control were comorbidities, continued exposure to irritants/triggers and poor adherence to therapy. The frequency of exacerbations was lower in patients with controlled asthma.

A fixed combination therapy with an inhaled corticosteroid and a long-acting $\beta_{2}$ agonist was reported by $77.0 \%$ of patients. A better asthma control and improved QoL were achieved with extrafine beclomethasone/formoterol compared to either budesonide/formoterol or fluticasone/salmeterol.
\end{abstract}

Conclusions: An improvement in asthma control and QoL can be achieved during a 1-year monitoring in a real life setting. Extrafine beclomethasone/formoterol was associated with significant benefit in terms of asthma control and QoL compared to large-particles combinations.

ClinicalTrials.gov number NCT01110460.

\section{Introduction}

According to international guidelines, once treatment has been established, therapeutic management of asthma should be based on asthma control, rather than asthma severity $[1,2]$. Patients with controlled asthma can prevent the majority of attacks, avoid daytime and nighttime symptoms, stay physically active and have reduced risk to exacerbate [3].

Recognizing the importance of the patient's perspective and of the poor correlation between lung function

\footnotetext{
*Correspondence: g.nicolini@chiesi.com

${ }^{2}$ Medical Affairs Department, Chiesi Farmaceutici S.p.A, Via Palermo 26/A, 43122, Parma, Italy

Full list of author information is available at the end of the article
}

and symptoms [3,4], clinical trials and clinical practice have increasingly focused on the assessment of asthma control. This is a general term that implies a global assessment of actual status and future risk including symptoms, reliever use, lung function, and the frequency/ severity of exacerbations [5]. The level of asthma control is usually categorized into controlled, partly controlled and uncontrolled [1]. Moreover, a positive correlation between asthma control and quality of life (QoL) has been demonstrated [3]. Awareness of patient reported outcomes such as asthma control and QoL is increasing, together with an emphasis in clinical research and by regulatory bodies because of their relevance in the overall treatment efficacy assessment [5].

\section{Ciomed Central}


The PRISMA (PRospectIve Study on asthMA control) observational study was designed to include a crosssectional phase and a 12-month prospective phase in order to estimate the level of asthma control in real life and its evolution during a 1-year follow up. The results of the cross-sectional phase of the PRISMA study, investigating the level of asthma control in 2853 patients with asthma recruited in 56 respiratory clinics in Italy have been recently published [6]. The main findings indicate that despite a high proportion of patients have controlled asthma, one third of patients are still uncontrolled or partly controlled. Previous studies were available evaluating the control of asthma but comprised smaller populations and with a less representative distribution throughout the country [7-11]. In the PRISMA study, patients filled in validated questionnaires for asthma control and QoL measurement and data were collected during visits by respiratory specialists. In contrast, previous studies have collected data by telephone interviews [7-9], web-based questionnaires [11-13], or postal screening questionnaires [14].

Moreover, all the above studies are cross-sectional but only prospective monitoring of patients' asthma control using composite measures can describe how this reflect asthma outcomes and/or future risks [5]. Unfortunately, no information is yet available on the rate of achievement of asthma control among poorly controlled asthma patients. It has been suggested that monitoring outcomes and taking appropriate action through regular visits may improve current levels of asthma control [15]. Behavioral factors such as smoking and non-adherence may reduce the efficacy of treatment and patients' perceptions influence these behaviors. Under-treatment may also be related to patients' underestimation of the significance of symptoms, and lack of awareness of achievable control. There is a need to raise patient expectations by increasing awareness of the QoL that could be attained.

The aim of the present study was to measure asthma control in a prospective 12 months observation period in patients whose asthma was classified as uncontrolled or partly controlled in a cross-sectional phase visit [6]. The prospective phase described in this manuscript aimed to evaluate the proportion of patients with uncontrolled or partly controlled asthma who achieve asthma control at 12 months. Secondary objectives were: to evaluate the reasons for lack of asthma control, perceived QoL and association with level of asthma control, the impact of pharmacological treatment, the number of exacerbations and the healthcare resource consumption.

\section{Methods}

Study design

The PRISMA study was designed to include a crosssectional phase [6] and a 12-month prospective phase in order to estimate the level of asthma control in real life and its evolution during a 1-year follow up. Clinic visits were performed every 3 months for a total of 5 visits throughout the 1-year study period and data were collected at each visit. The results of the cross-sectional phase of the PRISMA study were previously published [6]. Patients with uncontrolled or partly controlled asthma in the cross-sectional phase were included in the longitudinal phase of the study described hereafter. According to the observational study design, no randomisation procedure was implemented during the enrolment. The assignment of the patient to a particular therapeutic strategy was not defined in the study protocol but fell within current practice according to the physician's decision.

The protocol was approved by the Institutional Review Board of each centre, and informed written consent was obtained from each participant prior to study initiation.

\section{Patients}

The first fifty consecutive patients visiting 56 Italian pneumology centers were included in the cross-sectional phase of the PRISMA study if they satisfied the following criteria: i) provided written informed consent; ii) adult patients, smokers and non-smokers, with a previous asthma diagnosis of at least six months; iii) patients able to understand and fill in the questionnaires. Exclusion criteria were: i) patients included in clinical trials or who have been attending one in the last 12 weeks; ii) patients with severe and disabling diseases; iii) pregnant women.

Only patients who had uncontrolled or partly controlled asthma according to the ACT score in the crosssectional visit were included in the prospective phase here described.

\section{Patient reported outcomes}

The self-evaluating Asthma Control Test ${ }^{\text {TM }}$ (ACT) was used to determine the patients' level of disease control in the 4 weeks preceding each clinic visit $[4,16]$. The overall ACT score varies from 5 (very poor asthma control) to 25 (full asthma control) with scores ranging from 20 to 24 defining controlled asthma, scores ranging from 16 to 19 partly controlled asthma and scores $\leq 15$ uncontrolled asthma $[2,4]$. The ACT has been validated prospectively in several studies [5,17]. The EuroQoL-5D questionnaire [18] (EQ-5D) was used to determine the QoL perceived by the patient. It is a standardized selfrating test which refers to the day of rating applicable to a wide range of health conditions and treatments. EQ-5D provides a score where the maximum value of 1 denotes the best health status and 0 identifies a health status comparable to death. In addition, patients scaled their health on a visual analogue scale (VAS) ranging from 0 to 100 , with 0 as the worst possible health status and 100 as the 
best possible health status [18]. Questionnaires were completed by each participant at each visit.

\section{Other variables}

Current antiasthmatic therapies were recorded at each visit (in terms of active ingredient, dosage, duration and administration method). Patients were defined as treated with a specific drug if they had evidence of treatment for at least 5 consecutive days in the 3 months before the visit. For the comparison of asthma control level among treatments, only patients who had been on that therapy in the last 4 weeks were included in the analysis to match with ACT that evaluates asthma control in the last 4 weeks [6]. Possible reasons for poor control were described according to doctors' opinion.

Exacerbations were registered along with the consumption of healthcare resources due to asthma (hospitalizations, emergency room visits, outpatients visits) at each clinic visit.

Exacerbations were defined as worsening of symptoms requiring any of the following: an increase in therapy or systemic corticosteroids, unscheduled specialist visit or an access to an emergency room.

\section{Statistical analysis}

Due to the lack of prospective data on asthma control in observational studies, the sample size was estimated on the basis of the AIRE cross-sectional study [8]. The sample size was determined in order to have a relative error lower than $30 \%$ based on available literature data. It was estimated that a sample size of at least 1270 patients with uncontrolled or partly controlled asthma in the cross-sectional phase would have allowed to detect a rate of $5.1 \%$ of patients reaching optimal asthma control at the end of the 1-year prospective phase of the study, with a $95 \% \mathrm{CI}$ equal to $5.1 \pm 1.40 \%$ (estimating a $25 \%$ drop-out rate).

Summary statistics (mean, standard deviation) were provided for continuous variables, and absolute and relative frequency distribution was provided for categorical data. Comparisons between categorical variables were analyzed by the Chi-square test (or Fisher exact test, when appropriate). Comparisons between continuous variables were performed by the Kruskal-Wallis test. Post-hoc comparisons were performed, when applicable: in such cases, Bonferroni's correction was applied. Multivariate linear regression analyses were used in order to assess the association between the QoL (EQ-5D and VAS scores) and asthma control at the 12-month follow-up visit. Age, gender, educational level, BMI, smoking habits, asthma risk factors/triggers in the occupational environment, concomitant disease, QoL and asthma control (in the cross-sectional visit) were included as covariates. Since the independent variables have different scales, covariates were standardized. Significance was set at a two-tailed p-value of 0.05. All statistical analyses were performed by using the statistical analysis software "SAS version 9.2".

\section{Results}

\section{Study population}

Clinical characteristics of patients with uncontrolled or partly controlled asthma in the cross-sectional phase are summarized in Table 1 and patient flow during the 12month observation period is described in Figure 1. A total of 1017 uncontrolled or partly controlled patients were enrolled from January to October 2009 and followed up for 12 months with approximately $70 \%$ attending follow-up visits (Figure 1). The mean age was 46 years and $66.3 \%(n=674)$ were females. Patients with uncontrolled asthma were 566 (55.7\%), those with partly controlled asthma were 451 (44.3\%). Comparing patient clinical characteristics between the uncontrolled and partly controlled groups, a few significant differences were observed: uncontrolled patients reported that they had a poorer patient-doctor communication compared to the partly controlled patients $(25.3 \%$ vs. $16.2 \%, \mathrm{p}<$ $0.001)$; the percentage of obese patients was higher $(22.3 \%$ vs. $16.6 \%, \mathrm{p}=0.021)$ and sinusitis was more frequent among the uncontrolled patients $(13.4 \%$ vs. $8.4 \%$, $\mathrm{p}=0.012$ ).

The most frequently reported therapies (at least 5 consecutive days of therapy in the last 3 months) were: a fixed combination of an inhaled corticosteroid and a long acting $\beta_{2}$ agonist (ICS/LABA) in $48.3 \%$ of patients; leukotriene receptor antagonists in $23.6 \%$ and ICS in $11.2 \%$.

Clinical characteristics of patients $(n=739)$ attending the 12-month follow-up visit are summarized in Table 2.

\section{Asthma control}

An improvement in asthma control was observed at the first follow-up visit after 3 months, where $6.9 \%$ of patients achieved full asthma control (Figure 2). Furthermore, the proportion of patients achieving full asthma control increased over time, reaching $22.2 \%$ on the last visit, with $58.7 \%$ of patients having controlled asthma, $11.8 \%$ partly controlled asthma and $7.3 \%$ were still uncontrolled.

The main reasons for lack of asthma control as declared by treating physicians were comorbidities in $36.2 \%$ of patients, continued exposure to irritants/triggers in $34.0 \%$, and poor adherence to therapy in $27.0 \%$ (Table 3).

When comparing reasons for poor control after 1-year follow-up with those reported in the cross-sectional visit, poor adherence to therapy, lack of patient follow-up, poor patient-doctor communication and inadequate therapy were less frequently reported, whereas comorbidities were reported more frequently (Table 3 ). 
Table 1 Patients characteristics at the cross-sectional phase visit

\begin{tabular}{|c|c|c|c|}
\hline & Total & Partly controlled & Uncontrolled \\
\hline Number of patients, n (\%) & $1017(100)$ & $451(44.3)$ & $566(55.7)$ \\
\hline Age, years, mean (SD) & $46(15)$ & $45(15)$ & $47(15)$ \\
\hline \multicolumn{4}{|l|}{ Gender, n (\%) } \\
\hline Males & $343(33.7)$ & $160(35.5)$ & $183(32.3)$ \\
\hline Females & $674(66.3)$ & $291(64.5)$ & $383(67.7)$ \\
\hline Duration of asthma, years, mean (SD) & $17.4(13.0)$ & $16.4(12.7)$ & $18.2(13.2)$ \\
\hline \multicolumn{4}{|l|}{ Body mass index categories, n (\%) } \\
\hline Obese $\left(\geq 30 \mathrm{~kg} / \mathrm{m}^{2}\right)^{(1)}$ & $201(19.8)$ & $75(16.6)$ & $126(22.3)$ \\
\hline Overweight ( $\geq 25$ and $<30 \mathrm{~kg} / \mathrm{m}^{2}$ ) & $357(35.1)$ & $162(35.9)$ & $195(34.5)$ \\
\hline Normal weight ( $\geq 18.5$ and $<25 \mathrm{~kg} / \mathrm{m}^{2}$ ) & $390(38.4)$ & $188(41.7)$ & $202(35.7)$ \\
\hline Underweight $(<18.5$ kg/m²) & $32(3.2)$ & $12(2.7)$ & $20(3.5)$ \\
\hline Not available & $37(3.6)$ & $14(3.1)$ & $23(4.1)$ \\
\hline \multicolumn{4}{|l|}{ Smoking habits, n (\%) } \\
\hline Current smokers & $197(19.4)$ & $77(17.1)$ & $120(21.2)$ \\
\hline Non-smokers & $637(62.6)$ & $287(63.6)$ & $350(61.8)$ \\
\hline Ex-smokers ${ }^{(2)}$ & $174(17.1)$ & $86(19.1)$ & $88(15.6)$ \\
\hline Not available & $9(0.9)$ & $1(0.2)$ & $8(1.4)$ \\
\hline \multicolumn{4}{|l|}{ Concomitant diseases ${ }^{(3)}, \mathrm{n}(\%)$} \\
\hline Total & $640(62.9)$ & $287(63.6)$ & $353(62.4)$ \\
\hline Rhinitis & $362(35.6)$ & $164(36.4)$ & $198(35.0)$ \\
\hline Cardiovascular diseases & $151(14.8)$ & $70(15.5)$ & $81(14.3)$ \\
\hline Gastro-oesophageal reflux & $171(16.8)$ & $68(15.1)$ & $103(18.2)$ \\
\hline Sinusitis ${ }^{(4)}$ & $114(11.2)$ & $38(8.4)$ & $76(13.4)$ \\
\hline Nasal polyposis & $52(5.1)$ & $25(5.5)$ & $27(4.8)$ \\
\hline Type 2 diabetes & $39(3.8)$ & $14(3.1)$ & $25(4.4)$ \\
\hline Respiratory infections & $43(4.2)$ & $15(3.3)$ & $28(5.0)$ \\
\hline Psychological disturbances & $25(2.5)$ & $9(2.0)$ & $16(2.8)$ \\
\hline Type 1 diabetes & $5(0.5)$ & $2(0.4)$ & $3(0.5)$ \\
\hline Other diseases & $108(10.6)$ & $42(9.3)$ & $66(11.7)$ \\
\hline Quality of life, $n$ & 1010 & 448 & 562 \\
\hline EQ-5D ${ }^{(5)}$ score, mean (SD) & $0.72(0.2)$ & $0.75(0.2)$ & $0.69(0.2)$ \\
\hline EQ-5D ${ }^{(5)}$ VAS score, mean (SD) & $65.1(15.6)$ & $68.6(14.9)$ & $61.5(16.3)$ \\
\hline
\end{tabular}

Among patients treated with ICS/LABA combinations, in the last 4 weeks before the end of the study $(n=569)$, $19.0 \%$ had fully controlled asthma, $61.7 \%$ had controlled asthma, $12.0 \%$ had partly controlled asthma and $7.4 \%$ had uncontrolled asthma.

Three hundred and one patients were in treatment with the extrafine beclomethasone/formoterol (BDP/F) combination in a pressurized Metered Dose Inhaler (pMDI), 145 were in treatment with budesonide/formoterol (BUD/F) Dry Powder Inhaler (DPI) and 123 with fluticasone/salmeterol (FP/S; 46.3\% pMDI and 53.7\% DPI). When comparing the different available combinations, a greater proportion of patients treated with the extrafine $\mathrm{BDP} / \mathrm{F}$ combination achieved asthma control compared to patients treated with either BUD/F or FP/S (Table 4, Figure 3). The proportion of patients with full asthma control in the extrafine BDP/F-treated group was significantly greater than in the BUD/F-treated group (Bonferroni's corrected $\mathrm{p}<0.001$; Figure 3). Moreover, an improvement of 3 points in the ACT score was achieved by a significantly greater proportion of $\mathrm{BDP} / \mathrm{F}$ treated patients as compared to $\mathrm{BUD} / \mathrm{F}$ treated patients (Table 4). The probability of having full asthma control was higher in patients treated with extrafine BDP/F than 


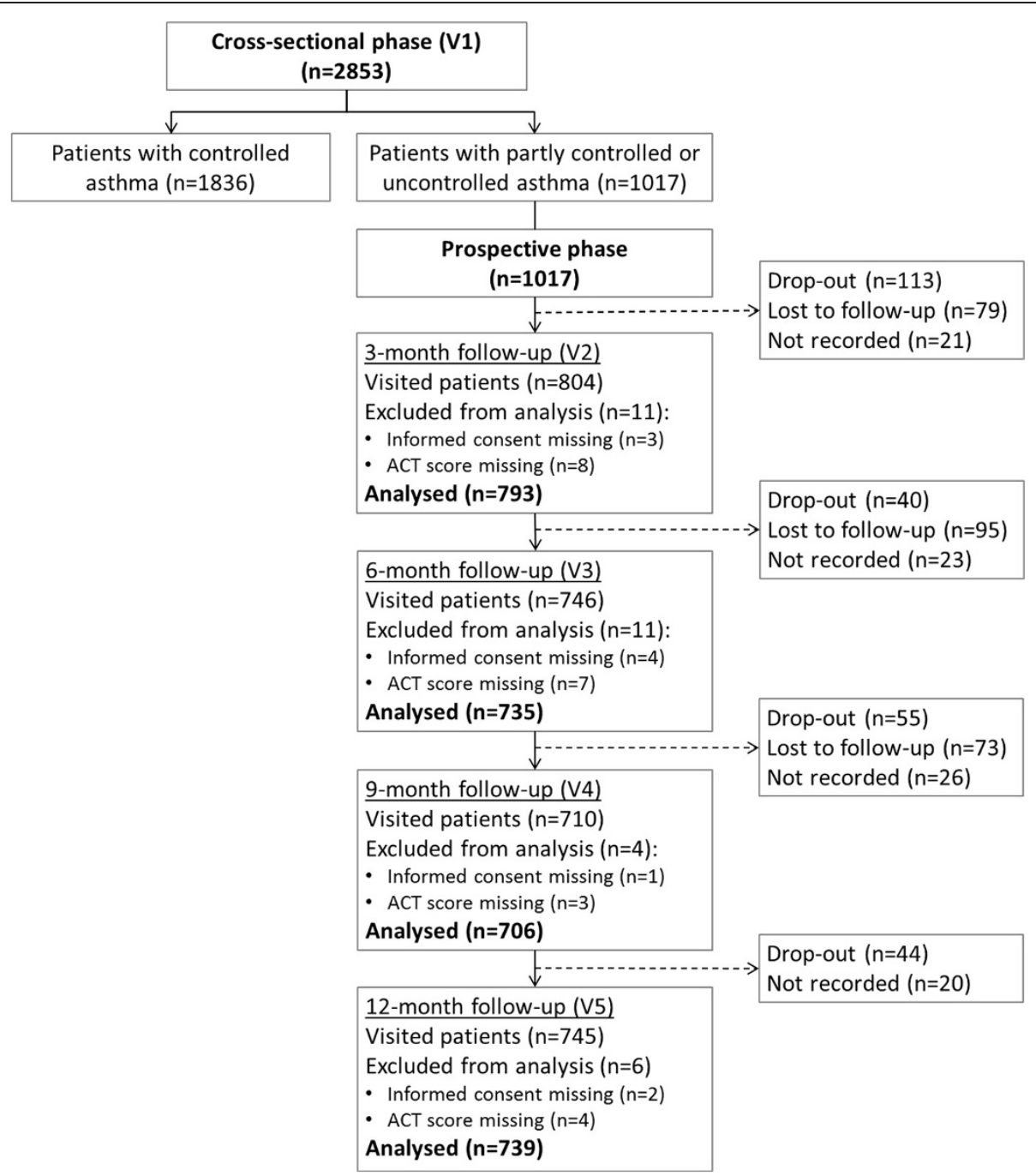

Figure 1 Patient flow. Patients were considered as drop-out if they definitely withdrew from the study; patients were considered as lost to follow-up if they missed one visit but they attended to a subsequent follow-up visit.

in those receiving $\mathrm{BUD} / \mathrm{F}$ (odds ratio 3.8; $95 \%$ adjusted CI: 1.733 to 8.374 ; Bonferroni's corrected $\mathrm{p}<0.001$ ) and FP/S (odds ratio 1.9; $95 \%$ adjusted CI: 0.957 to 3.699; Bonferroni's corrected $\mathrm{p}=0.075$ ).

The mean daily dose of ICS administered was approximately 2-fold lower for extrafine BDP/F compared to either BUD/F or FP/S (Table 4).

\section{Quality of life and exacerbations}

The EQ-5D and VAS scores at the 12-month follow-up visit were higher in patients with controlled asthma as compared to patients with partly controlled or uncontrolled asthma (Table 2). When covariates were taken into account, control at the 12-month visit, age and QoL in the cross-sectional visit were shown to be associated with 12-month QoL $(\mathrm{p}<0.001)$.
Patients treated with extrafine BDP/F had a significantly higher EQ-5D score compared to BUD/F (0.88 \pm 0.18 vs. $0.82 \pm 0.19$, Bonferroni's corrected $p=0.001$; Figure 4). Furthermore, a significantly higher VAS score was detected in the extrafine BDP/F-treated group $(82.7 \pm 12.5)$ compared to either BUD/F $(74.9 \pm$ 14.1, Bonferroni's corrected $\mathrm{p}<0.0001$ ) or FP/S-treated patients $(77.0 \pm 13.6$, Bonferroni's corrected $\mathrm{p}<$ 0.001; Figure 4).

A total of 589 exacerbations were reported during the 1-year follow up. The percentage of patients reporting exacerbations was lower, at all follow-up visits, in patients with controlled asthma compared to the sum of patients with partly controlled and uncontrolled asthma $(\mathrm{p}<0.001)$. In the last 3 months before the end of the study, at least one exacerbation was reported by $67 \%$ of patients with partly controlled and uncontrolled 
Table 2 Patient characteristics at the 12-month follow-up visit

\begin{tabular}{|c|c|c|c|c|c|}
\hline & Total & Controlled & Partly controlled & Uncontrolled & Overall $p$-value \\
\hline Number of patients, n (\%) & 739 & $598(80.9)$ & $87(11.8)$ & $54(7.3)$ & \\
\hline Smoking habits, n (\%) ${ }^{(1)}$ & & & & & 0.437 \\
\hline Current smokers & $136(18.4)$ & $113(18.9)$ & $14(16.1)$ & $9(16.7)$ & \\
\hline Non-smokers & $468(63.3)$ & $384(64.2)$ & $50(57.5)$ & $34(63.0)$ & \\
\hline Ex-smokers ${ }^{(2)}$ & $128(17.3)$ & $97(16.2)$ & $21(24.1)$ & $10(18.5)$ & \\
\hline Not available & $7(0.9)$ & $4(0.7)$ & $2(2.3)$ & $1(1.9)$ & \\
\hline Improvement of 3 points in ACT score, $\mathrm{n}(\%)$ & $642(86.9)$ & $572(95.7)$ & $55(63.2)$ & $15(27.8)$ & $<0.001^{(3)}$ \\
\hline Quality of life, $n$ & 733 & 593 & 86 & 54 & \\
\hline EQ-5D ${ }^{(4)}$ score, mean (SD) & $0.87(0.19)$ & $0.91(0.13)$ & $0.71(0.23)$ & $0.62(0.30)$ & $<0.001^{(5)}$ \\
\hline EQ-5D ${ }^{(4)}$ VAS score, mean (SD) & $80.0(13.6)$ & $83.8(10.2)$ & $67.2(12.1)$ & $58.9(16.0)$ & $<0.001^{(6)}$ \\
\hline \multicolumn{6}{|l|}{ Antiasthmatic therapy, n (\%) ${ }^{(7)}$} \\
\hline No therapy & $59(8.0)$ & $55(9.2)$ & $3(3.5)$ & $1(1.9)$ & - \\
\hline $\mathrm{ICS} / \mathrm{LABA}$ & $602(81.5)$ & $484(80.9)$ & $72(82.8)$ & $46(85.2)$ & - \\
\hline LTRA & $237(32.1)$ & $165(27.6)$ & $42(48.3)$ & $30(55.6)$ & - \\
\hline ICS & $71(9.6)$ & $55(9.2)$ & $7(8.1)$ & $9(16.7)$ & - \\
\hline Short-acting $\beta_{2}$ agonist & $42(5.7)$ & $21(3.5)$ & $13(14.9)$ & $8(14.8)$ & - \\
\hline
\end{tabular}

(1) Smoking habits was reported only at the cross-sectional phase visit; ${ }^{(2)}$ Patients who stopped smoking since at least one year; ${ }^{(3)}$ Bonferroni's corrected $\mathrm{p}<0.001$ for all comparisons; ${ }^{(4)}$ EQ-5D: EuroQoL-5D questionnaire; ${ }^{(5)}$ Bonferroni's corrected $\mathrm{p}<0.001$ patients with controlled asthma vs. patients with partly controlled and uncontrolled asthma; Bonferroni's corrected $p=0.060$ patients with partly controlled asthma vs. patients with uncontrolled asthma; ${ }^{(6)}$ Bonferroni's corrected $p<0.001$ patients with controlled asthma vs. patients with partly controlled and uncontrolled asthma; Bonferroni's corrected $p=0.004$ patients with partly controlled asthma vs. patients with uncontrolled asthma; ${ }^{(7)}$ Data are percentage of patients in each category of asthma control reporting therapies for at least 5 consecutive days in the last 3 months; patients could have more than one pharmacologic class therapy; ICS: inhaled corticosteroids; LABA: long-acting $\beta_{2}$ agonist; LTRA: leukotriene receptor antagonists.

asthma compared to $6 \%$ of patients with controlled asthma $(\mathrm{p}<0.001)$.

The percentage of patients reporting exacerbations in the last 3 months before the 12-month visit was $13.3 \%$ in patients treated with extrafine $\mathrm{BDP} / \mathrm{F}, 13.1 \%$ in

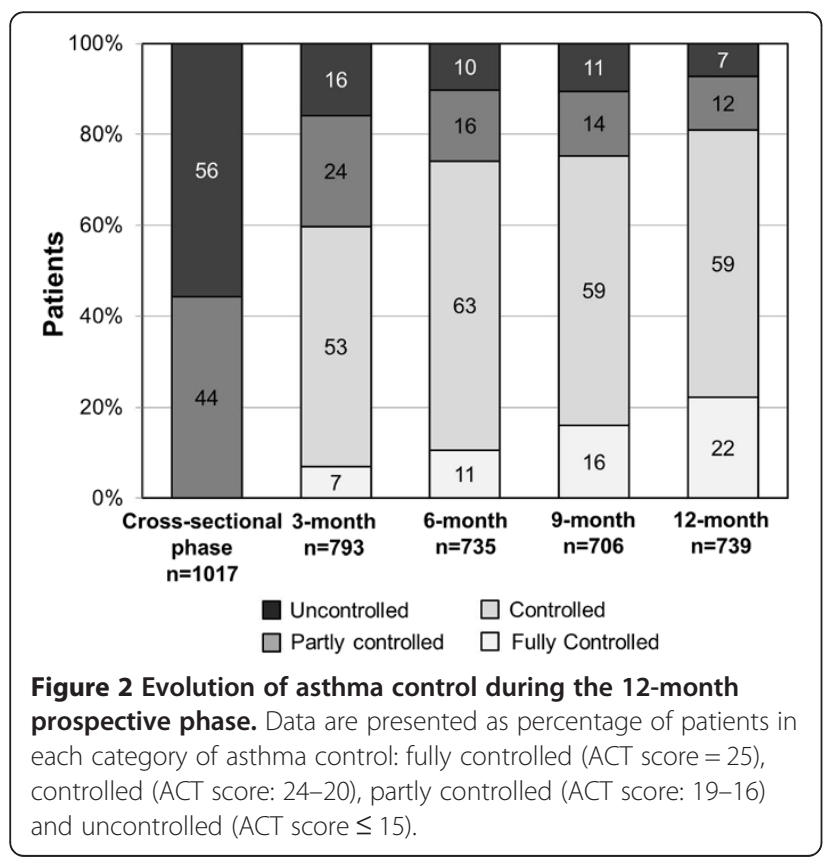

patients treated with BUD/F and $20.3 \%$ in patients treated with $\mathrm{FP} / \mathrm{S}$.

\section{Consumption of healthcare resources}

A significant decrease in healthcare resource consumption was detected during the 1-year follow-up (Figure 5). The percentage of patients requiring an outpatient visit in the last 3 months before the 12-month visit was reduced approximately 3 -fold to $24.5 \%$ (compared to $62 \%$ at the beginning of the study, $\mathrm{p}<0.001)$. The proportion of patients that were admitted to hospital was also reduced from $5.8 \%$ in the cross-sectional visit to $0.5 \%$ in the 12 -month follow-up visit $(\mathrm{p}<0.001)$. The frequency of emergency room visits was also significantly reduced, from $15.4 \%$ in the cross-sectional visit to $1.9 \%$ in the last follow-up visit $(\mathrm{p}<0.001)$.

\section{Discussion}

PRISMA is the first prospective observational study specifically designed to evaluate the proportion of patients achieving asthma control during a 1-year follow-up in real life conditions.

The main findings from this prospective study demonstrate that $22.2 \%$ of patients that previously had partly controlled or uncontrolled asthma $(n=739)$ achieved full asthma control after 1 year, $58.7 \%$ had controlled asthma, 
Table 3 Comparison between the reasons for lack of asthma control at the cross-sectional visit and at the 12-month follow-up visit

\begin{tabular}{|c|c|c|c|}
\hline \multirow{2}{*}{$\begin{array}{l}\text { Reasons for lack of asthma control, } \\
\qquad \mathrm{n}(\%)\end{array}$} & Cross-sectional phase visit & 12-month follow-up visit & \multirow[b]{2}{*}{ p-value ${ }^{(2)}$} \\
\hline & Total $n=1017$ & Total $n=141$ & \\
\hline Comorbidities & $154(15.1)$ & $51(36.2)$ & $<0.001$ \\
\hline Continued exposure to irritants/triggers & $295(29.0)$ & $48(34.0)$ & 0.238 \\
\hline Poor adherence to therapy & $440(43.3)$ & $38(27.0)$ & $<0.001$ \\
\hline Smoking habits & $154(15.1)$ & $11(7.8)$ & 0.020 \\
\hline Lack of patient follow up & $405(39.8)$ & $9(6.4)$ & $<0.001$ \\
\hline Inadequate therapy & $202(19.9)$ & $8(5.7)$ & $<0.001$ \\
\hline Poor patient-doctor communication & $216(21.2)$ & $5(3.6)$ & $<0.001$ \\
\hline Inadequate inhalation technique & $63(6.2)$ & $4(2.8)$ & 0.125 \\
\hline
\end{tabular}

(1) According to the doctor's opinion; Patients could have more than one reason; ${ }^{(2)}$ Fisher exact test between the cross-sectional visit and the 12 -month follow-up visit.

$11.8 \%$ had partly controlled asthma and $7.3 \%$ were still uncontrolled.

Among those patients who, after the 1-year follow-up, did not attain asthma control $(\mathrm{n}=141)$, the reasons were anyway different, according to the physician assessment, from those at study start. Actually, when comparing the last visit of the prospective phase with the cross-sectional visit, reasons for lack of asthma control changed from lack of adequate therapy/follow-up/communication or smoking habits, i.e. all external factors that therefore can be improved by a better asthma care, to the presence of comorbidities. This finding suggests that during 1-year monitoring in real life conditions, an improvement in patient behavioral factors that contribute to the lack of asthma control such as adherence to medication, patientdoctor communication and follow up can be obtained. An additional observation coming from the present study is that the rate of outpatients visits, hospitalizations and emergency room visits was reduced approximately 3-fold by the end of the follow-up period. This is in line with the AIRE study that examined the use of healthcare resources in 7 European countries and showed that worse asthma control was associated with an increased requirement for unscheduled care and higher costs [8].

Moreover, our findings indicate that asthma control can be achieved in a great proportion of patients treated

Table 4 Characteristics of patients treated with ICS/LABA fixed combinations for at least 4 weeks before the 12-month follow-up visit

\begin{tabular}{|c|c|c|c|c|c|}
\hline & Total $n=569$ & BDP/F extrafine $n=301$ & BUD/F $n=145$ & $\mathrm{FP} / \mathrm{S} \mathrm{n}=123$ & Overall p-value \\
\hline Level of asthma control, n (\%) & & & & & $0.001^{(1)}$ \\
\hline Fully controlled & $108(19.0)$ & 77 (25.6) & $12(8.3)$ & $19(15.4)$ & \\
\hline Controlled & $351(61.7)$ & $173(57.5)$ & $102(70.3)$ & $76(61.8)$ & \\
\hline Partly controlled & $68(12.0)$ & $31(10.3)$ & $18(12.4)$ & 19 (15.4) & \\
\hline Uncontrolled & $42(7.4)$ & $20(6.6)$ & $13(9.0)$ & $9(7.3)$ & \\
\hline Current smokers, n (\%) & $110(19.3)$ & $69(22.9)$ & $25(17.2)$ & $16(13.0)$ & 0.617 \\
\hline Fully controlled & $25(22.7)$ & $20(29.0)$ & $3(12.0)$ & $2(12.5)$ & 0.135 \\
\hline Controlled & $66(60.0)$ & $39(56.5)$ & $17(68.0)$ & $10(62.5)$ & \\
\hline Partly controlled & $12(10.9)$ & $7(10.1)$ & $3(12.0)$ & $2(12.5)$ & \\
\hline Uncontrolled & $7(6.4)$ & $3(4.4)$ & $2(8.0)$ & $2(12.5)$ & \\
\hline ACT score, mean (SD) & $21.5(3.4)$ & $22.0(3.4)$ & 20.7 (3.6) & $21.3(3.3)$ & $<0.001^{(2)}$ \\
\hline Improvement of 3 points in ACT score, $\mathrm{n}(\%)$ & $493(86.6)$ & $268(89.0)$ & $116(80.0)$ & $109(88.6)$ & $0.024^{(3)}$ \\
\hline Daily Dose of ICS, $n$ & 537 & 287 & 141 & 122 & \\
\hline Mean mcg (SD) & NA & $318.8(114.3)$ & $651.1(291.2)$ & $750.6(371.7)$ & $<0.001^{(4)}$ \\
\hline Patients with exacerbation, $\mathrm{n}(\%){ }^{(5)}$ & $84(14.8)$ & $40(13.3)$ & $19(13.1)$ & $25(20.3)$ & 0.145 \\
\hline
\end{tabular}




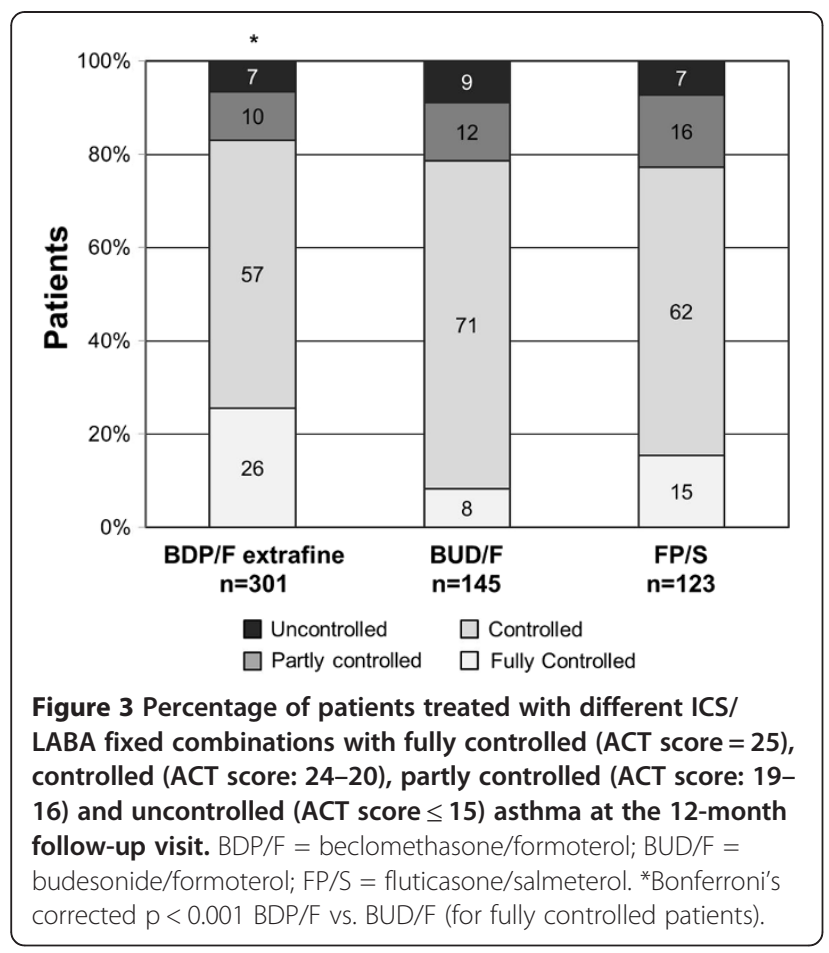

with the ICS/LABA fixed combinations, which is in agreement with recent observational studies reporting the ICS/LABA combination being the most effective treatment choice [19-21]. In a 12-month office-based observational study, patients recently started on FP/S combination, had significantly greater improvement in both asthma control and QoL, compared with patients newly started on

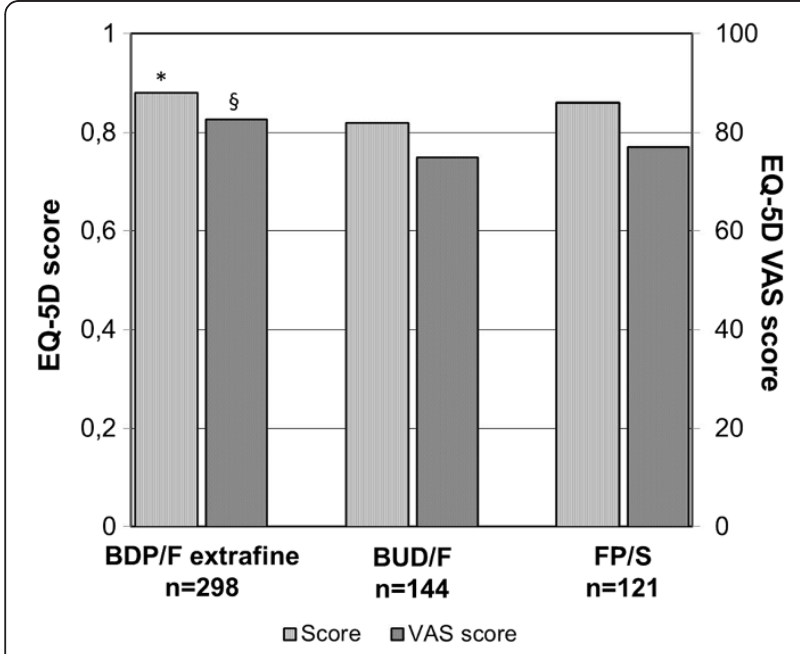

Figure 4 Quality of life (EQ-5D score and VAS) in patients treated with different ICS/LABA fixed combinations at the 12month follow-up visit. BDP/F = beclomethasone/formoterol; BUD/ $\mathrm{F}=$ budesonide/formoterol; FP/S = fluticasone/salmeterol. Data are means. *Bonferroni's corrected $p=0.001 \mathrm{BDP} / \mathrm{F}$ vs. BUD/F;

${ }^{\S}$ Bonferroni's corrected $p<0.001$ BDP/F vs. BUD/F and FP/S.

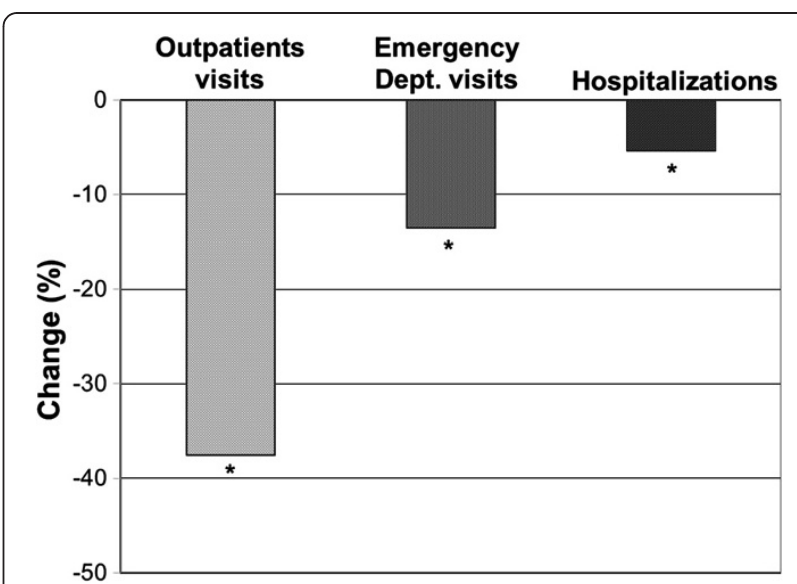

Figure 5 Percentage change in healthcare resource consumption due to asthma from 3 months before the crosssectional phase visit to 3 months before the 12-month followup visit. ${ }^{*} p<0.001$ for all comparisons.

montelukast [20]. Another study with a 12-month real life observation period showed a greater change in asthma control score in $\mathrm{FP} / \mathrm{S}$ treated patients compared to other forms of treatment that were in accordance with asthma treatment guidelines (including BUD/F but not including $\mathrm{BDP} / \mathrm{F}$ extrafine) [21]. We observed that a greater proportion of patients treated with extrafine BDP/F fixed combination achieved good asthma control and the maximum ACT score (i.e. full control) compared to either BUD/F or $\mathrm{FP} / \mathrm{S}$-treated patients, the difference being significant versus BUD/F. Moreover, the proportion of patients achieving a clinically meaningful change in ACT score (3 points) was greater in $\mathrm{BDP} / \mathrm{F}$ treated patients compared to $\mathrm{BUD} / \mathrm{F}$ treated patients. We considered only patients who had been on the same therapy in the last 4 weeks for the comparison of asthma control level among treatments to match with ACT that evaluates asthma control in the last 4 weeks.

As regards QoL assessed by EQ-5D, an improvement of approximately $21 \%$ was observed after 1 year in the whole population studied. When looking at patients treated with ICS/LABA fixed combinations, extrafine $\mathrm{BDP} / \mathrm{F}$-treated patients experienced significantly higher QoL compared to either BUD/F or FP/S-treated patients at the end of the 12-month observation period. These results are consistent with those obtained in the crosssectional phase of the PRISMA study [6] and may be attributed to the formulation of this combination, which is characterized by extrafine particles able to reach and treat the whole bronchial tree, including small airways [22]. Indeed, asthma control and QoL correlate with functional parameters reflecting small airways function and improvements in ventilation heterogeneity are associated with improvements in symptoms [23,24]. 
A better asthma control with extrafine BDP/F combination compared to BUD/F and FP/S combinations was recently shown in two observational cross-sectional studies $[6,25]$. This is also confirmed by results from a recent observational study which showed that initiating or increasing therapy with an extrafine beclomethasone formulation results in similar or better asthma control compared with non-extrafine fluticasone [26].

The evidence of improvement in asthma control and QoL in patients treated with extrafine formulations compared to large particles formulations is supported by randomized controlled trials (RCTs) $[27,28]$. Moreover, an RCT demonstrated that a greater asthma control was achieved in patients treated with extrafine BDP/F combination compared to the same drugs administered with separate inhalers delivering large particles [29]. This evidence is particularly interesting when compared with similarly designed studies with the other two available combinations, as shown in a recently published review, thus supporting the concept of greater efficacy of $\mathrm{BDP} / \mathrm{F}$ due to extrafine particles [30].

The difference in asthma control was detected despite the lower ICS dose and the higher percentage of smokers in the BDP/F patient cohort. This is of particular interest since smoking is associated with an increased risk of poor control [31,32] and asthmatic smokers are less responsive to ICS therapy [33,34]. Our findings support the concept that the tobacco smoke-drug particle interactions, which contribute to drug resistance, are less likely to occur in case of extra-fine formulations [35]. Together, these results suggest that asthmatic smokers can particularly benefit from extrafine BDP/F combination. This is also supported by a recently published prospective real-life study showing significant improvements in pulmonary function and asthma control in patients treated with extrafine BDP/F combination with the same treatment benefits observed in former or current smokers compared with non-smoking asthmatics [36].

Someone may argue that the level of asthma control detected in the present study is quite high compared to the GOAL study in which patients were stepped up for a 1 -year period to the highest recommended dose of $\mathrm{FP} / \mathrm{S}$ combination [37]. However, this difference can be explained by the different patient population, definition of control and way of measuring it. In the GOAL study only patients with uncontrolled asthma were recruited and the definition of control as from asthma international guidelines included lung function. Moreover, the definition of "total control" used in the GOAL study was very stringent (defined by achievement of all specified criteria for 7 weeks in each 8-week period) and now abandoned [1,2]. By contrast, the ACT used in the present study is a validated patient reported outcome $[4,5,16,17]$ and does not include lung function which has been shown having minimal impact on the reliability, responsiveness, and both crosssectional and prospective validity of the instrument [38].

Observational studies present some limitations such as the possibility of unmeasured or unrecognized confounding factors or influences on prescribing. These results should be interpreted in light of the inherent limitations of nonrandomized, uncontrolled studies. However, these limits are balanced by the broader applicability of observational real life data on larger and more representative patient populations with common co-morbidities and that can identify clinically important differences among treatments [39]. By contrast, RCTs have limited external validity as they have been performed on highly selected patient populations and most of the participants currently under asthma treatment in the community are not represented [40].

In conclusion, the main findings from this prospective phase of the PRISMA study demonstrate that an improvement in asthma control can be achieved during a 1-year monitoring in a real life setting. Furthermore, patients have improved QoL and reduced hospital visits. Fixed combination of extrafine BDP/F was associated with significant benefit in terms of asthma control and QoL compared to large-particles combinations, this advantage likely being attributed to the extrafine formulation.

\section{Competing interest}

Giovanni Cremonesi: Employee of Chiesi Farmaceutici S.p.A, Eleonora Ingrassia: Employee of Chiesi Farmaceutici S.p.A, Gabriele Nicolini: Employee of Chiesi Farmaceutici S.p.A, Luigi Allegra: Consultant fees: GSK (I), Astrazeneca (I), Chiesi (I), Boehringer Mannheim (I), Zambon (I), IBSA (CH), Procter \& Gamble (UK), Cotherix (USA). Reimbursements for attending a symposia: GSK (I), Astrazeneca (I), Chiesi (I), Boehringer Ingelheim (I), Eurodrug NL) Angelini (I). Fees for speaking: Menarini (I), Boehringer Ingelheim (I), IBSA (CH), Eurodrug (NL). Funds for research: Angelini (I). Funds for members of staff: Cotherix (USA) Exalee (USA), IBSA (CH). All other authors declare no competing interest.

\section{Authors' contributions}

All of the authors contributed to the definition of the study protocol, data interpretation and writing of the manuscript. All of the authors read and approved the final manuscript

\section{Acknowledgements}

Best enrollers (more than 70 patients enrolled) for PRISMA study were: $C$. Terzano (Policlinico Umberto I, Roma), M. Sofia (AORN Monaldi, Napoli), P. Menna (Ospedale Cristo Re, Roma), F. Pezzuto (Ospedale "Amico Gaetano Fucito"Mercato San Severino, Slaerno), V. Dipietro (Ospedale G.F. Ingrassia, Palermo), G. Girbino (Policlinico G. Martino, Messina).

Participants with significant contribution ( $>69$ enrolled patients $>51$ ) were: $P$. Bosco (Centro Catanese di Medicina e Chirurgia, Catania), M. Sforza (ASL BAT Andria, Andria), D. Ansalone (Ospedale G. da Procida, Salerno), D. De Sanctis (Ospedale di Atri, Atri), G. Failla (Ospedale Regina Apostolorum, Albano Laziale, Roma), V. Formisano (Ospedale Civile, Maddaloni, Caserta), A. Pennisi (Casa di Cura MUSUMECI Gecas, Gravina, Catania), W. Castellani (Ospedale Careggi, Firenze), M. Papale (I.F.O. Regina Elena, Roma), E. Giua Marassi (Ospedale Pneumologico R. Binaghi, Cagliari), R. Perra (I.N.R.C.A. Centro per le Broncopneumopatie IRCCS, Cagliari), E. Piccolini (Ospedale Santo Spirito, Casale Monferrato, Alessandria), S. Privitera (Centro per la Prevenzione e il Monitoraggio per l'insufficienza respiratoria, Giarre, Catania), R. Tazza (ASL4 Terni, Terni), M. Manzella (Servizio Territoriale di Pneumologia, San Severo, Foggia), G. Simon (Az. Osp. Villa Sofia CTO, Palermo), E. Marchi (I.N.R.C.A. 
Centro per le Broncopneumopatie, Casatenovo, Lecco), M. Nalin (Ospedale Santa Maria degli Angeli, Pordenone), V. Roncoroni (Ospedale Valduce, Como). Participants ( $>50$ enrolled patients) were: F. Crismancich (Casa di Cura Pineta del Carso, Trieste), L. Ferramosca (Ospedale Civile Pispico, Poggiardo, Lecce), M. La Porta (Ospedale Ferro Branciforti Capra, Leonforte, Enna), N. Luzi (Ospedale Santo Spirito, Roma), B. Moscatelli (Ospedale San Giovanni Calibita FBF, Roma), S. Nardini (Ospedale Civile, Vittorio Veneto, Treviso), O. Resta (Policlinico Consorziale, Bari), P. Scavalli (Distretto 5 AUSL di Viterbo, Civita Castellana), A. Tubaldi (Ospedale di Macerata, Macerata), C. Zamprogna (Ospedale Amedeo di Savoia, Torino), A. Zedda (Ospedale S. Maria della Pietà Camilliani, Casoria, Napoli), V. Di Rienzo (ASL Frosinone, Frosinone), R. Numeroso (Casa di Cura Clinica San Carlo, Paderno Dugnano, Milano), E. Berardi (Ospedale M. Bufalini, Cesena), A. Scaramozzino (Policlinico Madonna della Consolazione, Reggio Calabria), G. Cremona (Istituto Scientifico San Raffaele, Milano), M. Torlasco (Ospedale Civile, Voghera), M. P. Foschino (Ospedale D'Avanzo, Foggia), O. Guarino (Ospedale S. Pietro Fatebenefratelli, Roma), G. Idotta (Ospedale Civile, Cittadella, Padova), R. Capra (Azienda Ospedaliera di Parma, Parma), L. Donateo (Azienda Unità Sanitaria Locale Lecce), M. Naldi (Ospedale San Donato, Arezzo), L. Bartolucci (Ospedale Narni-Amelia, Narni), V. Valenti (Policlinico San Donato, San Donato M.se), P. Rottoli (Az. Osp. Univ. Senese, Policlinico Le Scotte, Siena), P. Candoli (Ospedale Umberto I, Lugo, Ravenna), A. Moretti (Ospedale Sant' Andrea, La Spezia), M. Bevilacqua (Ospedale Civile CPO, Ostia, Roma), G. Cocco (A.O.R.N. A. Cardarelli, Napoli), R. Aquilina (Ospedale Unificato d'Imperia, Imperia). The authors thank Medidata for data collection and analysis and Dr Selene Mogavero and Dr Colin G. Egan (Primula Multimedia) who provided skilful editorial assistance.

\section{Author details}

${ }^{1}$ Respiratory Diseases Unit, Department of Cardiovascular and Respiratory Sciences, 'Sapienza' University of Rome, Viale del Policlinico 155, 00161, Rome, Italy. ${ }^{2}$ Medical Affairs Department, Chiesi Farmaceutici S.p.A, Via Palermo 26/A, 43122, Parma, Italy. ${ }^{3}$ Institute of Respiratory Medicine, University of Messina, Via Consolare Valeri, Gazzi, 98125, Messina, Italy. ${ }^{4}$ Department of Respiratory Medicine, Azienda Ospedaliera Monaldi, Second University of Naples, Via Leonardo Bianchi, 80131, Naples, Italy.

${ }^{5}$ Thoracopulmonary Department, University of Milan, Fondazione IRCCS Cá Granda Ospedale Maggiore Policlinico, Via Francesco Sforza 28, 20122, Milan, Italy.

Received: 18 October 2012 Accepted: 29 November 2012

Published: 6 December 2012

\section{References}

1. Global Initiative for Asthma (GINA): Global Strategy for Asthma Management and Prevention; Updated 2010. Available from: http://www.ginasthma.org/.

2. National Heart, Lung, and Blood Institute: National Asthma Education and Prevention Program. Expert Panel Report 3: Guidelines for the Diagnosis and Management of Asthma; Full Report 2007. Available from: http://www.nhlbi. nih.gov/.

3. Bateman ED, Bousquet J, Keech ML, Busse WW, Clark TJ, Pedersen SE: The correlation between asthma control and health status: the GOAL study. Eur Respir J 2007, 29:56-62.

4. Baiardini I, Braido F, Bindslev-Jensen C, Bousquet PJ, Brzoza Z, Canonica GW, et al: Recommendations for assessing patient-reported outcomes and health-related quality of life in patients with urticaria: a GA(2) LEN taskforce position paper. Allergy 2011, 66:840-844.

5. Reddel HK, Taylor DR, Bateman ED, Boulet LP, Boushey HA, Busse WW, et al: An official American Thoracic Society/European Respiratory Society statement: asthma control and exacerbations: standardizing endpoints for clinical asthma trials and clinical practice. Am J Respir Crit Care Med 2009, 180:59-99.

6. Allegra L, Cremonesi G, Girbino G, Ingrassia E, Marsico S, Nicolini G, et al: Real-life prospective study on asthma control in Italy: cross-sectional phase results. Respir Med 2012, 106:205-214.

7. Partridge MR, van der Molen T, Myrseth SE, Busse WW: Attitudes and actions of asthma patients on regular maintenance therapy: the INSPIRE study. BMC Pulm Med 2006, 6:13.

8. Rabe KF, Vermeire PA, Soriano JB, Maier WC: Clinical management of asthma in 1999: the asthma insights and reality in Europe (AIRE) study. Eur Respir J 2000, 16:802-807.
9. Vermeire PA, Rabe KF, Soriano JB, Maier WC: Asthma control and differences in management practices across seven European countries. Respir Med 2002, 96:142-149.

10. Cazzoletti L, Marcon A, Janson C, Corsico A, Jarvis D, Pin I, et al: Therapy and health economics group of the European community respiratory health survey. Asthma control in Europe: a real-world evaluation based on an international population-based study. J Allergy Clin Immunol 2007, 120:1360-1367.

11. Demoly P, Paggiaro P, Plaza V, Bolge SC, Kannan H, Sohier B, et al: Prevalence of asthma control among adults in France, Germany, Italy, Spain and the UK. Eur Respir Rev 2009, 18:105-112.

12. Demoly P, Gueron B, Annunziata K, Adamek L, Walters RD: Update on asthma control in five European countries: results of a 2008 survey. Eur Respir Rev 2010, 19:150-157.

13. Demoly P, Annunziata K, Gubba E, Adamek L: Repeated cross-sectional survey of patient-reported asthma control in Europe in the past 5 years. Eur Respir Rev 2012, 21:66-74.

14. De Marco R, Bugiani M, Cazzoletti L, Carosso A, Accordini S, Buriani O, et al: The control of asthma in Italy. A multicentre descriptive study on young adults with doctor diagnosed current asthma. Allergy 2003, 58:221-228.

15. Horne R, Price D, Cleland J, Costa R, Covey D, Gruffydd-Jones K, et al: Can asthma control be improved by understanding the patient's perspective? BMC Pulm Med 2007, 7:8.

16. Nathan RA, Sorkness CA, Kosinski M, Schatz M, Li JT, Marcus P, et al: Development of the asthma control test: a survey for assessing asthma control. J Allergy Clin Immunol 2004, 113:59-65.

17. Schatz M, Sorkness CA, Li JT, Marcus P, Murray JJ, Nathan RA, et al: Asthma Control Test: reliability, validity, and responsiveness in patients not previously followed by asthma specialists. J Allergy Clin Immunol 2006, 117:549-556.

18. EuroQol group: EQ-5D-5L User Guide, Basic Information on How to Use the EQ5D-5L Instrument; Updated 2011. Available from: http://www.euroqol.org/.

19. O'Connor RD, Rosenzweig JR, Stanford RH, Gilmore AS, Ryskina KL, Legorreta AP, et al: Asthma-related exacerbations, therapy switching, and therapy discontinuation: a comparison of 3 commonly used controller regimens. Ann Allergy Asthma Immunol 2005, 95:535-540.

20. O'Connor RD, Gilmore AS, Manjunath R, Stanford RH, Legorreta AP, Jhingran PM: Comparing outcomes in patients with persistent asthma: a registry of two therapeutic alternatives. Curr Med Res Opin 2006, 22:453-461.

21. Trautmann M, Banik N, Tews JT, Jörres RA, Nowak D: Efficacy of the combination of fluticasone propionate and salmeterol in patients with moderate persistent asthma within a "real-life" setting. Eur J Med Res 2007, 12:255-263.

22. De Backer W, Devolder A, Poli G, Acerbi D, Monno R, Herpich C, et al: Lung deposition of BDP/formoterol HFA pMDI in healthy volunteers, asthmatic, and COPD patients. J Aerosol Med Pulm Drug Deliv 2010, 23:137-148.

23. Farah CS, King GG, Brown NJ, Downie SR, Kermode JA, Hardaker KM, et al: The role of the small airways in the clinical expression of asthma in adults. J Allergy Clin Immunol 2012, 129:381-387.

24. Takeda T, Oga T, Niimi A, Matsumoto H, Ito I, Yamaguchi M, et al: Relationship between small airway function and health status, dyspnea and disease control in asthma. Respiration 2010, 80:120-126.

25. Müller V, Gálffy G, Eszes N, Losonczy G, Bizzi A, Nicolini G, et al: Asthma control in patients receiving inhaled corticosteroid and long-acting beta2-agonist fixed combinations. A real-life study comparing dry powder inhalers and a pressurized metered dose inhaler extrafine formulation. BMC Pulm Med 2011, 11:40.

26. Price D, Martin RJ, Barnes N, Dorinsky P, Israel E, Roche N, et al: Prescribing practices and asthma control with hydrofluoroalkane-beclomethasone and fluticasone: a real-world observational study. J Allergy Clin Immunol 2010, 126:511-518.

27. Molimard M, Martinat Y, Rogeaux Y, Moyse D, Pello JY, Giraud V: Improvement of asthma control with beclomethasone extrafine aerosol compared to fluticasone and budesonide. Respir Med 2005, 99:770-778.

28. Juniper EF, Price DB, Stampone PA, Creemers JP, Mol SJ, Fireman P. Clinically important improvements in asthma-specific QoL, but no difference in conventional clinical indexes in patients changed from conventional beclomethasone dipropionate to approximately half the dose of extrafine beclomethasone dipropionate. Chest 2002, 121:1824-1832. 
29. Huchon G, Magnussen H, Chuchalin A, Dymek L, Gonod FB, Bousquet J: Lung function and asthma control with beclomethasone and formoterol in a single inhaler. Respir Med 2009, 103:41-49.

30. Barnes PJ, Nicolini G, Bizzi A, Spinola M, Singh D: Do inhaled corticosteroid/long-acting beta2-agonist fixed combinations provide superior clinical benefits compared with separate inhalers? A literature reappraisal. Allergy Asthma Proc 2012, 33(2):140-144.

31. McLeish AC, Zvolensky MJ: Asthma and cigarette smoking: a review of the empirical literature. J Asthma 2010, 47:345-361.

32. Haughney J, Price D, Kaplan A, Chrystyn H, Horne R, May N, et al: Achieving asthma control in practice: understanding the reasons for poor control. Respir Med 2008, 102:1681-1693.

33. Tomlinson JE, McMahon AD, Chaudhuri R, Thompson JM, Wood SF, Thomson NC: Efficacy of low and high dose inhaled corticosteroid in smokers vs. non-smokers with mild asthma. Thorax 2005, 60:282-287.

34. Thomson NC, Chaudhuri R: Asthma in smokers: challenges and opportunities. Curr Opin Pulm Med 2009, 15:39-45.

35. Invernizzi G, Ruprecht A, De Marco C, Mazza R, Nicolini G, Boffi R: Inhaled steroid/tobacco smoke particle interactions: a new light on steroid resistance. Respir Res 2009, 10:48.

36. Brusselle G, Peché R, Van den Brande P, Verhulst A, Hollanders W, Bruhwyler $J$ : Real-life effectiveness of extrafine beclometasone dipropionate/ formoterol in adults with persistent asthma according to smoking status. Respir Med 2012, 106(6):811-819.

37. Bateman ED, Boushey HA, Bousquet J, Busse WW, Clark TJ, Pauwels RA, et al: Can guideline-defined asthma control be achieved? the gaining optimal asthma ControL study. Am J Respir Crit Care Med 2004, 170:836-844.

38. Juniper EF, O'Byrne PM, Roberts JN: Measuring asthma control in group studies: do we need airway calibre and rescue beta2-agonist use? Respir Med 2001, 95:319-323.

39. Silverman SL: From randomized controlled trials to observational studies. Am J Med 2009, 122:114-120.

40. Herland K, Akselsen JP, Skjønsberg OH, Bjermer L: How representative are clinical study patients with asthma or COPD for a larger "real life" population of patients with obstructive lung disease? Respir Med 2005, 99:11-19.

doi:10.1186/1465-9921-13-112

Cite this article as: Terzano et al:: 1-year prospective real life monitoring of asthma control and quality of life in Italy. Respiratory Research 2012 13:112.

\section{Submit your next manuscript to BioMed Central and take full advantage of:}

- Convenient online submission

- Thorough peer review

- No space constraints or color figure charges

- Immediate publication on acceptance

- Inclusion in PubMed, CAS, Scopus and Google Scholar

- Research which is freely available for redistribution 